\title{
Ultrasonik Yöntemler ile Çelik-lif Takviyeli Betonda Eğilme Çatlaklarının Derinlik Tayini
}

\author{
Ahmet Serhan KIRLANGIÇ ${ }^{1}$
}

ÖZ

Betonda eğilme çatlaklarının derinliklerin tespit edilmesi, yapısal elemanların kalan yük taşıma kapasitelerinin tayini için önem taşımakladır. Uygulamada, mevcut tahribatsız ultrasonik test yöntemleri çatlak derinliğinin tespitinden ziyade ya elemanların kalınlıklarının ölçülmesinde ya da mukavemet tayininde kullanılmaktadır. Bir cisim içinde yayılmakta olan ultrasonik dalgalar bir çatlak ile karşılaştıkları zaman dalga karakteristiklerinde değişim gözlemlenir. Bu değişimin takibi ve ölçümü ile çatlak derinliğinin tayini mümkündür. $\mathrm{Bu}$ makale, bu yaklaşıma dayanarak geliştirilen tanı metodunu, 7 adet çelik-lifli beton kiriş numune $\left(50 \times 10 \times 10 \mathrm{~cm}^{3}\right)$ üzerinde gerçekleştirilmiş olan ultrasonik testler üzerinden incelemektedir. Kiriş numeneler çatlak-kontrollü üç-noktal1-eğilme testi ile belli bir çatlak derinliğine ulaşılana kadar hasara uğratılmış ve akabinde gerçekleştirilen ultrasonik testler ile dalga yayılımı kaydedilmiştir. Kaydedilen dalga sinyal serileri, ayrık wavelet dönüşüm ve frekans-dalganumarası analizi gibi dijital sinyal işleme teknikleri ile analiz edilerek iki tip tanı indeksi elde edilmiştir. İlk tanı indeksi malzeme sönüm katsayısı $\alpha$, dalga sönümünü; diğer tanı indeksi 'dağılım indeksi $D I$ ' ise, dalgaların faz hızındaki dağılımı temsil etmektedir. Her iki tanı indeksinin de çatlak tespiti ve derinlik tahmininde faydalı oldukları görülmüştür.

Anahtar Kelimeler: Tahribatsız muayene, çatlak derinlik ölçümü, çelik-lif takviyeli beton, ultrasonik yüzey dalgaları, dalga sönümü, dalga dağılımı.

\section{ABSTRACT \\ Ultrasound based Crack Depth Estimation in Steel-fiber Reinforced Concrete}

Estimation of the depth of surface-breaking cracks caused by bending in concrete has crucial importance in order to predict the remaining load capacity of a structural member. In practice, ultrasonic tests are the most commonly used non-destructive methods to assess the condition of concrete. However, the commercial ultrasound-based methods focus on the estimation of thickness of the structural element rather than the crack depth. The cracks cause dispersion

\footnotetext{
Not: Bu yaz1

- Yayın Kurulu’na 21 Eylül 2020 günü ulaşmıștır. 1 Mart 2021 günü yayımlanmak üzere kabul edilmiştir.

- 31 Temmuz 2022 gününe kadar tartışmaya açıktır.

- https://doi.org/10.18400/tekderg.797412

1 Bahçeşehir Üniversitesi, İnşaat Mühendisliği Bölümü, İstanbul - serhan.kirlangic@eng.bau.edu.tr https://orcid.org/0000-0003-3638-4475
} 
and attenuation in the propagating waves, and thus by monitoring the changes in these wave characteristics, diagnostic indexes correlated with the crack depth can be defined. This paper explains this approach through the tests performed on seven laboratory-scale steel-fiber reinforced concrete beams $\left(50 \times 10 \times 10 \mathrm{~cm}^{3}\right)$. The beams are loaded under the crack-controlled three-point bending test until a specific crack depth is reached. These beams are then subjected to ultrasonic testing to acquire the propagating surface waves. The recorded signals are analysed by utilizing signal processing techniques, including discrete wavelet transform and frequency-wavenumber analysis in order to extract two diagnostic features, namely, material attenuation coefficient and dispersion index. It is shown that both diagnostic features are able to detect the crack and estimate its depth.

Keywords: Non-destructive testing, crack depth estimation, steel-fiber reinforced concrete, ultrasonic surface waves, dispersion, attenuation.

\section{GİRiş}

Betonarme yapı elemanlarının hasar durumlarının belirlenmesi çoğunlukla görsel muayene ile yapılmaktadır. Bu yöntemin sübjektif ve zaman alıcı olması sebebiyle yakın geçmişte tahribatsız muayene yöntemleri beton yapılar için yaygınlaşmaya başlamıştır. Bu alanda birçok akademik araştırma olduğu gibi ticari olarak betonun malzeme özelliklerini tahribatsız tayin edecek ekipmanlar da günümüzde mevcuttur. Endüstride kendine yer bulmuş olan en yaygın metotlardan bazıları; ultrason, yer radarı (ground penetrating radar, GPR) ve özdirenç (electrical resistivity, ER) yöntemleridir. Ultrasonik metotlar mekanik dalgaların beton içindeki hızının tespitine dayanırken [1,2], GPR elektro-manyetik dalgaların yayılmasının takip edilmesine dayanır. GPR aslında yeraltı profilini çıkarmak için geliştirilmiş bir jeofizik uygulaması olmakla birlikte beton döşeme ve yol kaplamalarının kalınlık ve donatı tespiti için de kullanılabilmektedir [3]. Elektrik direnç yöntemi ise betonun elektrik akımına gösterdiği direncin ölçülmesine dayanmakta olup, betonarme donatısındaki korozyonun tespitinde kullanılabilmektedir [4]. Uygulamada, bu yöntemler arasında ultrasonik yöntemler betondaki çatlakların tespitinde öne çıkmaktadır.

Ultrasonik tahribatsız yöntemler, genellikle beton içinde yayılan dalgaların geçiş hızının ölçülmesi ve bu karakteristik malzeme özelliğinin referans değer ile karşılaştırılarak betonun dayanımının dolaylı olarak tahmin edilmesine dayanır. Bu yöntem ultrasonik geçiş hızı (UPV) olarak bilinmektedir [1]. UPV'den uyarlanmış bir başka yöntem olan ultrasonik itkieko (UPE) ise, beton elemanların kalınlığının yanı sıra betonun içinde olup yüzeyde görünmeyen çatlak veya boşluk gibi kusurların tespiti için kullanılmaktadır [2]. Bu klasik ultrasonik test metotlarında bir tip dalga karakteristiği, birincil-dalga (P-dalgası) hızı, tanı parametresi olarak elde edilir. Ancak P-dalgası hızı, yüzeyde görünen eğilme tipi çatlakların derinliğinin tayininde, çatlak ucunun şekline ve yönüne bağlı olarak, yanıltıcı sonuçlar verebilmektedir [5]. Klasik ultrasonik testlerin bu eksikliği, yüzey dalgalarını kullanarak aşılabilir. Yüzey dalgalarından, penetrasyon derinlikleri oranında, içinde yayıldığı malzeme hakkında bilgi edilebilinir. Bu sebeple, yüzey dalgalarının tahribatsız muayene amaçlı birçok farklı uygulamada kullanımı bulunmaktadır. Örneğin, yeraltındaki tesisatın tespiti [6], yeraltı boşluklarının boyutlandırılması $[7,8]$ ve beton yapı elemanlarının durum tayini $[9,10]$ bu uygulamalardan bazılarıdır. 
Yüzey dalgaları içinde yayıldıkları cismin malzeme özelliklerine göre ilerledikleri mesafe boyunca sönümlenirler. Eğer yayılan dalgalar ilk kaynak noktasından itibaren farklı mesafelerde kayıt altına alınırsa, dalga-boylarının genliklerinin değişiminden malzeme sönüm katsayısı tespit edilebilinir. Sönüm katsayısı malzemenin karakteristik bir özelliği olduğundan, bu katsayıdaki değişim takip edilerek malzemedeki yüzey kusurlarının ne kadar derine indiğini tayin etmek mümkün olabilmektedir [11,12]. İkinci bir tanı parametresi de yüzey dalgaların faz hızlarının dağıılımından elde edilebilinir. Sınırsız katı cisimlerde, tüm dalga boyları aynı hızda hareket eder. Cisimde çatlak veya boşluk gibi bir kusur olması durumunda ise, bu engel ile karşılaşan dalga-boylarından engelin boyutları ile orantılı olanlar dağılım özelliği gösterir. Başka bir ifade ile, bu dalga-boylarının hızlarında engel ile etkileşime girmeyen dalga-boylarına kıyasla değişim gözlenir. Bu durum dalgalarda dağı̆lım (dispersiyon) olarak bilinir ve malzemenin hasar tayininde faydalanılmaktadır [13,14,15].

Literatürde, beton yapı elemanlarında eğilme çatlak derinliğinin ultrasonik yöntemler ile tayinine dönük araştırmalarda çoğunlukla, laboratuvar numuneleri içinde yaratılmış yapay düzgün şekilli çatlak veya kusurlar üzerinde çalışılmıştır. Bu araştırmalarda, çatlak derinliği ile sönüm ve dispersiyon gibi dalga yayılım karakteristiklerinin çatlak derinliği ile olan ilişkisi niceliksel olarak ortaya konulmuştur [11-15]. Ancak beton yapı elemanlarında oluşan eğilme çatlakların gerçek formları çok daha komplekstir. Bu yüzden, yüzeyde görünen eğilme çatlaklarının derinliklerinin, dolayısıyla yapı elemanının en-kesit alanındaki kaybının, doğru tayin edilebilmesi için gerçekçi şekildeki çatlaklar üzerinde detaylı araştırmalara ihtiyaç duyulmaktadır. Bu ihtiyaç doğrultusunda, bu araştırmada, beton yapı elemanlarında oluşan eğilme çatlaklarının derinliğini tayin edebilmek için ultrasonik dalgalara dayanan bir metot geliştirilmiştir. Bu amaçla, önce farklı derecelerde hasara maruz bırakılmış çelik-lif takviyeli beton kiriş numuneler üzerinde çok-kanallı ultrasonik testler gerçekleştirilmiştir. Sonrasında, hasar tanı indekslerini dalga sönüm ve hız dağılım davranışlardan elde edecek sinyal işleme algoritması geliştirilmiştir. Çelik-lif takviyeli betonların ultrasonik yöntemler ile muayenesine yönelik önceki araştırmaların büyük bir çoğunluğu malzeme karakterizasyonu amacıyla gerçekleştirilmiş olup, çelik-lifli betonlarda ultrasonik yöntemler ile çatlak derinliği tayinine dönük araştırmalar ise çok sınırlıdır. Bu konuda, dikkate değer tek çalışmada ise yüzey dalgalarının genliğinin dalga hızına kıyasla çatlak derinliğine daha duyarlı olduğu tespiti yapılmıştır [16]. Burada sunulan çalışmada çelik-lifli betonlarda eğilme çatlağı derinliği tayini için ilk kez çok-kanallı ultrasonik test konfigürasyonu kullanılarak, dalga hızı dışındaki dalga özelliklerinden (sönüm ve dağılım) hasar tanı indeksleri elde edilmiştir.

\section{MEKANIK DALGA YAYILIM KARAKTERISTIKLERI}

$\mathrm{Bu}$ çalışmada, çatlak derinliği tayini için aşağıda açıklanan mekanik dalga yayılım karakteristiklerinden faydalanılmıştır.

\subsection{Malzeme Sönüm Katsayısı}

Yayılan dalgalarda sönüm, malzeme sönümü ve geometrik yayılım nedeniyle oluşur. İçsel sürtünmeden kaynaklanan malzeme sönümü, bir malzeme özelliği olan sönüm katsayısı $\alpha$ ile ifade edilir ve yayılan dalgalardan aşağıdaki denklem ile belirlenebilinir [17]: 
$\alpha=\frac{1}{x_{i+1}-x_{i}}\left[\ln \left(\frac{A_{i+1}}{A_{i}}\right)-\beta \ln \left(\frac{x_{i+1}}{x_{i}}\right)\right]$

Burada $A_{i}$ etki noktasından $x_{\mathrm{i}}$ mesafesinde ölçülmüş olan dalganın genliğidir. $\beta$ ise dalga cephesindeki geometrik büyümeden kaynaklı sönüm ile ilgili olan geometrik yayılım sabitidir ve yüzey dalgaları için $-0,5^{\prime}$ e eşittir. $A_{i}$ dalga genliği olabileceği gibi Fourier dönüşüm (FT) gibi sinyal işleme teknikleri kullanılarak elde edilen belirli bir frekans veya frekans aralığının büyüklüğü de olabilir.

\subsection{Faz Hızı Dağılımı (Dispersiyon)}

Homojen bir cismin yüzeyinde yayılan yüzey dalgalarını oluşturan tüm dalga-boyları sabit Rayleigh dalga hızında $V_{R}$ hareket eder. Cisimde bir engel ile karşılaşan dalga-boylarının faz hızlarında ise, engelin boyutları ile orantılı olarak, dağılım gözlenir. Faz hızındaki bu dağılım "dispersiyon" olarak adlandırılır. Dispersiyon dalga-boyuna ve dolayısıyla frekansa bağlıdır. Dalga boyu $\lambda$, faz hızı $V_{p h}$ ve frekans $f$ arasındaki ilişki aşağıdaki gibidir:

$\lambda=V_{p h} / f$

Yayılan dalgalarda dispersiyon, “dispersiyon eğrisi” olarak adlandırılan frekans $f$ vs. faz hızı $V_{p h}$ grafiği ile görselleştirilir. Yüzey dalgalarında dispersiyon tespiti için gerekli prosedür üç adımda özetlenebilinir [18]:

(i) "ofset-zaman" $(x-t)$ domaininde dalga sinyallerinin kayıt edilmesi,

(ii) sinyallerin "ofset-zaman" $(x-t)$ domaininden "frekans-dalganumarası" domaine dönüştürülmesiyle " $f-k$ spektrumunun" elde edilmesi,

(iii) $f-k$ spektrumundan faz hızı $V_{p h}$ hesabının yapılarak dispersiyon eğrilerinin çizimi.

Burada, dalganumarası $k$ ile dalgaboyu $\lambda$ aşağıdaki ilişki ile birbirine bağlıdır:

$k=2 \pi / \lambda$

Denklem 2 ve 3 kullanılarak, (iii) adımda bahsedilen $f-k$ spektrumundan faz hızı, başka bir deyişle dispersiyon eğrisi, aşağıdaki gibi elde edinilir:

$V_{p h}=2 \pi(f / k)$

Dalga yayılımındaki dispersiyonun ölçümü için farklı konumlarda dalga sinyallerinin kayıt altına alınmasına izin veren çok kanallı bir test konfigürasyonunun kullanılması gerekmektedir. Daha sonra, kaydedilen bu sinyallerin iki boyutlu Fourier dönüşümü (2D-FT) ile ofset-zaman $p(t, x)$ domaininden frekans-dalganumarası domainine $P(f, \kappa)$ aşağıdaki gibi geçiş yapılarak $f-k$ spektrumu elde edilir:

$P(f, \kappa)=\int_{-\infty}^{\infty} \int_{-\infty}^{\infty} p(t, x) e^{-i(2 \pi f t-\kappa x)} d t d x$ 
2D-FT ile elde edilen $f-k$ spektrumunda direk yayılan, yansıyan ve iletilen dalgalar tespit edilebilinmektedir. Bu spektrumda, çatlakların dalgaların yayılımında sebep oldukları dağılım etkisi de gözlemlenerek, çatlak boyut tahmini gerçekleştirilebilinir.

\section{LABORATUVAR ÇALIŞMALARI}

Yukarıda bahsi geçen dalga yayılım karakteristiklerinin eğilme çatlakları içeren beton yapı elemanları içindeki davranışların incelenmesi için laboratuvar ölçekli çelik-lifli beton numuneler üzerinde aşağıda detayları verilen çalışmalar gerçekleştirilmiştir.

\subsection{Beton numunelerin Hazırlanması}

Ultrasonik testleri gerçekleştirmek için eğilme çatlakları içeren 7 adet $50 \times 10 \times 10 \mathrm{~cm}^{3}$ boyutlarında çelik lif takviyeli beton kiriş numune üretilmiştir. Çelik lif takviyeli numune tercih edilmesinin sebebi, sünek numuneler elde etmek ve EN 14651 [19] test prosedürü ile çatlak oluşumunu kontrol altında tutarak farklı seviyelerde çatlak oluşturabilmektir. Bu çelik lif takviyeli beton (SFRC) kiriş numunelerin $1 \mathrm{~m}^{3}$ tasarım karışımı: 1053,9 kg kaba agrega, 797,2 kg kum, 310 kg CEM I 42.5R tipi çimento, 201,7 kg su, 3,5 kg süper-akışkanlaştırıcı ve $39,3 \mathrm{~kg} 35 \mathrm{~mm}$ uzunluğunda $0.55 \mathrm{~mm}$ çapında (boyluluk oranı =64) kanca uçlu çelik elyaf içermektedir. Maksimum dane çapı $24 \mathrm{~mm}$, çelik-lifin çekme dayanımı ise 1345 MPa'dir.

28 günlük kür süresinden sonra, altı adet kiriş, EN 14651 standardına uygun olarak $8 \mathrm{~mm}$ derinliğinde çentik açıldıktan sonra $100 \mathrm{kN}$ yükleme kapasiteli MTS marka servo-hidrolik kontrollü eğilme deneyi cihazı kullanılarak, üç-nokta-eğilme testine tabi tutulmuş ve gerçek şekilli dikey düşümlü çatlaklar oluşturulmuştur. Eğilme testleri yükleme hızı $0.07 \mathrm{~mm} /$ dakika olarak ve yükleme başlığı deplasmanı kontrollü olarak gerçekleştirilmiştir. Yüklemeler sırasında zaman, yük, yükleme başlığı deplasmanı ve çatlak ağzı açıklığı deplasmanı (CMOD) verileri sürekli olarak kaydedilmiştir. Eğilme testleri sırasında, CMOD değeri önceden belirlenmiş bir çatlak genişliğine ulaştığında yükleme durdurulmuştur; böylece her kiriş için farklı bir çatlak derinliği elde edilmiştir.

Tablo 1 - Kiriş Özellikleri

\begin{tabular}{|c|c|c|c|}
\hline Kiriş & $\begin{array}{c}\text { Ĕgilme Dayanımı } \\
\text { (MPa) }\end{array}$ & $\begin{array}{c}\text { CMOD } \\
(\mathbf{m m})\end{array}$ & $\begin{array}{c}\text { Çatlak Derinliği } \\
(\mathbf{m m})\end{array}$ \\
\hline B1 & N/A & N/A & N/A \\
\hline B2 & 5.34 & 1.00 & 53 \\
\hline B3 & 4.79 & 1.25 & 58 \\
\hline B4 & 3.65 & 1.50 & 79 \\
\hline B5 & 4.49 & 1.75 & 76 \\
\hline B6 & 4.63 & 2.00 & 90 \\
\hline B7 & 4.93 & 2.25 & 94 \\
\hline
\end{tabular}




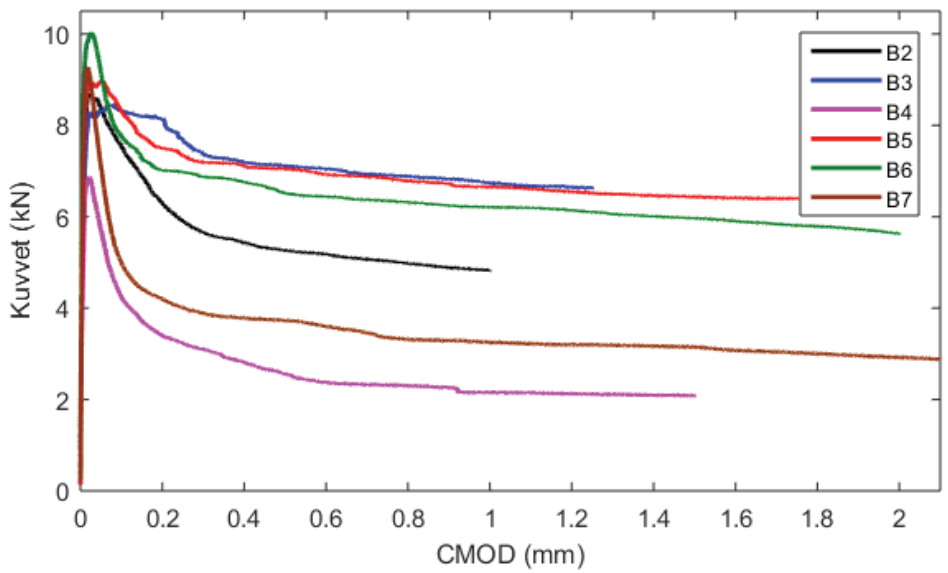

Şekil 1 - Yük vs. CMOD ĕgrileri

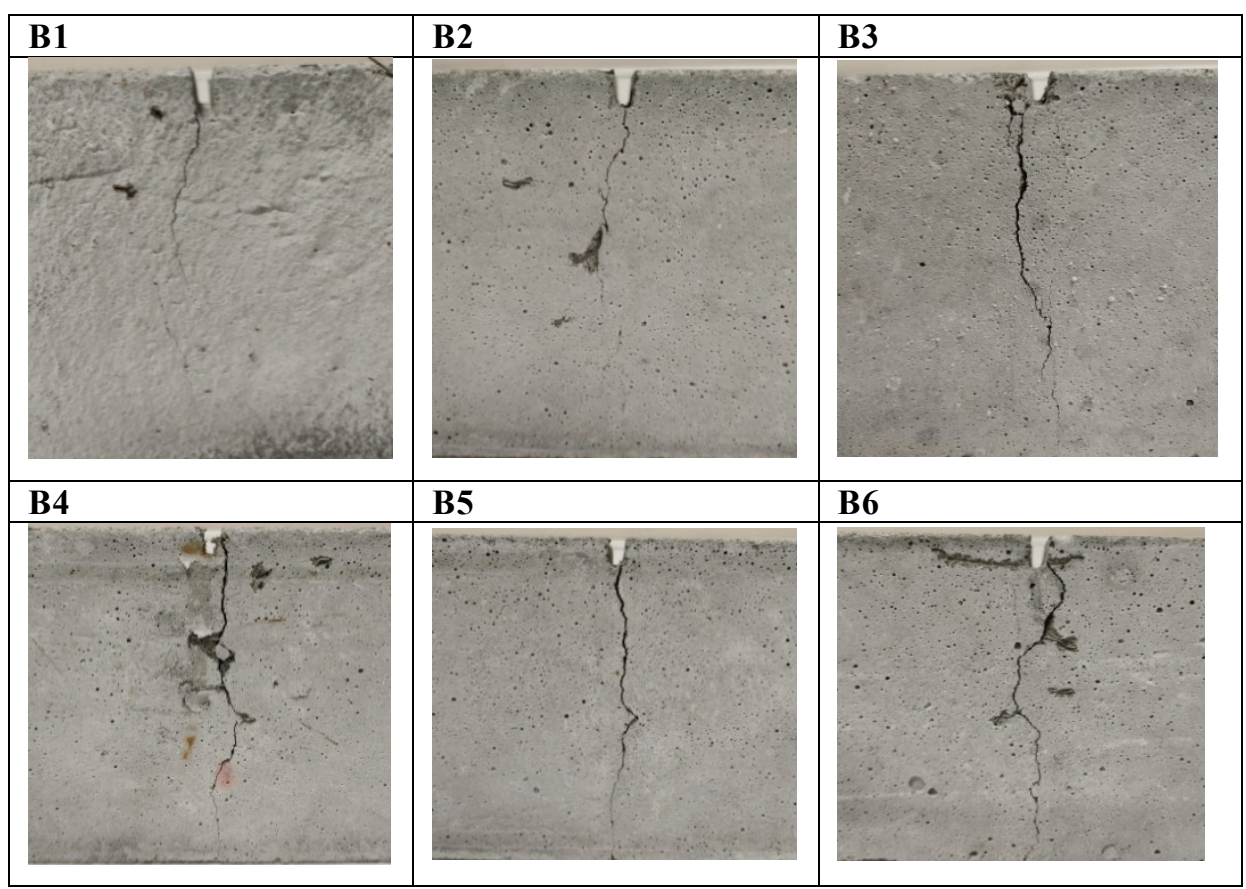

Şekil 2 - Kiriş numunelerdeki eğilme çatlakları

Eğilme testlerinden elde edilen yükleme vs. CMOD eğrileri Şekil 1 gösterilmiştir. Şekildeki eğrilerde görülebileceği gibi maksimum CMOD değerleri $0,25 \mathrm{~mm}$ 'lik bir artışla $1,00 \mathrm{~mm}$ ile $2,25 \mathrm{~mm}$ arasında değişecek şekilde eğilme testleri tamamlanmıştır. Kirişler bu maksimum CMOD değeri artan şekilde B1, B2, B3, B4, B5, B6 ve B7 olarak kodlandırılmıştır; B1 
hasarsız kontrol kirişini, B7 ise en çok hasar içeren kirişi ifade etmektedir. Şekil 2'de gösterilmiş olan çatlakların görsel muayene sonucu ölçülen derinlikleri Tablo 1'de verildiği gibi 53 ila $94 \mathrm{~mm}$ arasında değişmektedir. Kirişlerin eğilme mukavemetleri ise $3.65 \mathrm{MPa}$ ila 5.34 MPa (Tablo 1) arasında değişmekte olup, ortalaması 4.64 MPa'dır. Son olarak, basınç dayanımı, EN 12390-3'e [20] uygun olarak test edilen üç adet $160 \mathrm{~mm}$ çapında ve $320 \mathrm{~mm}$ uzunluğunla silindirik numuneden $31,8 \mathrm{MPa}$ olarak ölçülmüştür.

\subsection{Ultrasonik Testler}

Ultrasonik test düzeneği: ultrasonik bir pundit (Proceq Pundit Lab), $54 \mathrm{kHz}$ rezonans frekansına sahip iki transdüser ve bir bilgisayardan oluşmaktadır (Şekil 3). Transdüserlerden biri, transmitör olarak kullanılarak çatlaktan $15 \mathrm{~cm}$ uzağa, alıcı olarak kullanılan diğer transdüser ise $18 \mathrm{~cm}$ uzunluğundaki bir çizgi boyunca kaydırılarak farklı noktalara yerleştirilmiştir. Alıcı transdüser birbirinden $2 \mathrm{~cm}$ mesafe ile ayrılmış 10 farklı konuma yerleştirilmiştir. Transmitör, alıcı transdüserin ilk konumuna göre $6 \mathrm{~cm}$ uzaklıktadır. Transdüserler ve kiriş numuneler arasına vakum gresi sürülerek yüzey teması tam olarak sağlanmıştır. Her lokasyonda, 100 adet ultrasonik sinyalin ortalaması alındıktan sonra bu ortalama sinyal bilgisayarda kaydedilmiştir. Ultrasonik testlerin sonunda, her bir numune için farklı noktalarda kaydedilmiş 10 sinyalden oluşan bir veri seti elde edilmiştir.

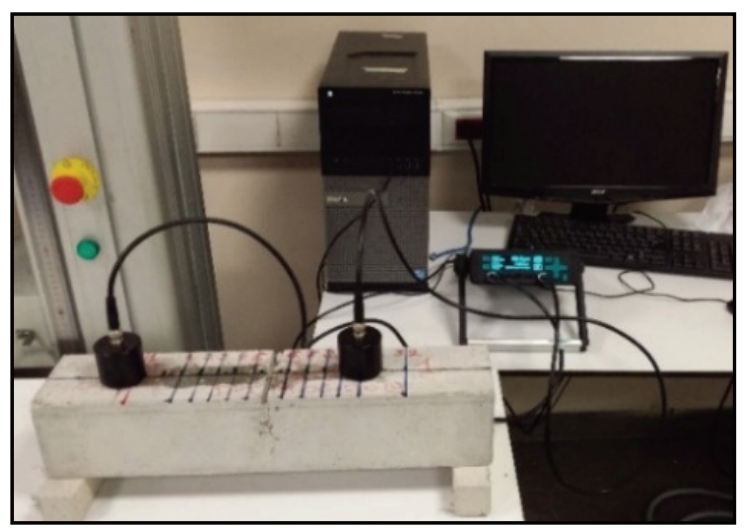

Şekil 3 - Test düzeneği

\subsection{Ultrasonik Test Sinyalleri}

Kontrol kirişi (B1) ile en derin çatlağa sahip olan kirişten (B7) elde edilen ultrasonik yüzey dalga sinyalleri normalize edilerek Şekil 4'te gösterilmiştir. B7'dan elde edilen sinyallerde çatlaktan sonra dalga cephelerindeki önemli azalma açıkça görülmektedir. B7'de 6 nolu alıcıdaki maksimum dalga genliğinde komşusu olan 5 nolu alıcıya göre \%90 düşüş gözlemlenmiştir. Yüzey dalgasının varış zamanlarına göre hesaplanan Rayleigh dalga hızı $V_{R}$, sağlam kiriş için $2528 \mathrm{~m} / \mathrm{s}$ bulunmuştur. B7 için ise, çatlak nedeniyle, çatlaktan önce ve sonra iki farklı $\mathrm{V}_{\mathrm{R}}$ tespit edilmiştir. Çatlaktan önce (1-5 nolu alıcılar kullanılarak) $V_{R} 2659$ $\mathrm{m} / \mathrm{s}$ olarak belirlenmiştir ki; bu değer B1'de ölçülen hız ile uyumludur. Çatlaktan sonra ise, dalga cephesindeki azalma sebebiyle (6-10 nolu alıcılar için), net bir varış zamanı tespit 
edilmemiştir. Çatlak ilk varması gereken dalga cephesini önemli ölçüde sönümlendirmekte; ardından ise çatlak ucundan kırılarak daha geç ulaşan dalgalar belirmektedir. Çatlaktan geçen dalga cephesi çok zayıf olduğu için, $V_{R}$ güvenle belirlenememiştir ve bu nedenle çatlak derinliğinin bir ölçüsü olarak değerlendirilmemiştir. Bunun yerine, ultrasonik test sinyalleri üzerinden dalga sönümüne ve dispersiyonuna dayanan iki diyagnostik tanı indeksi aşağıda anlatıldığı gibi geliştirilmiştir.
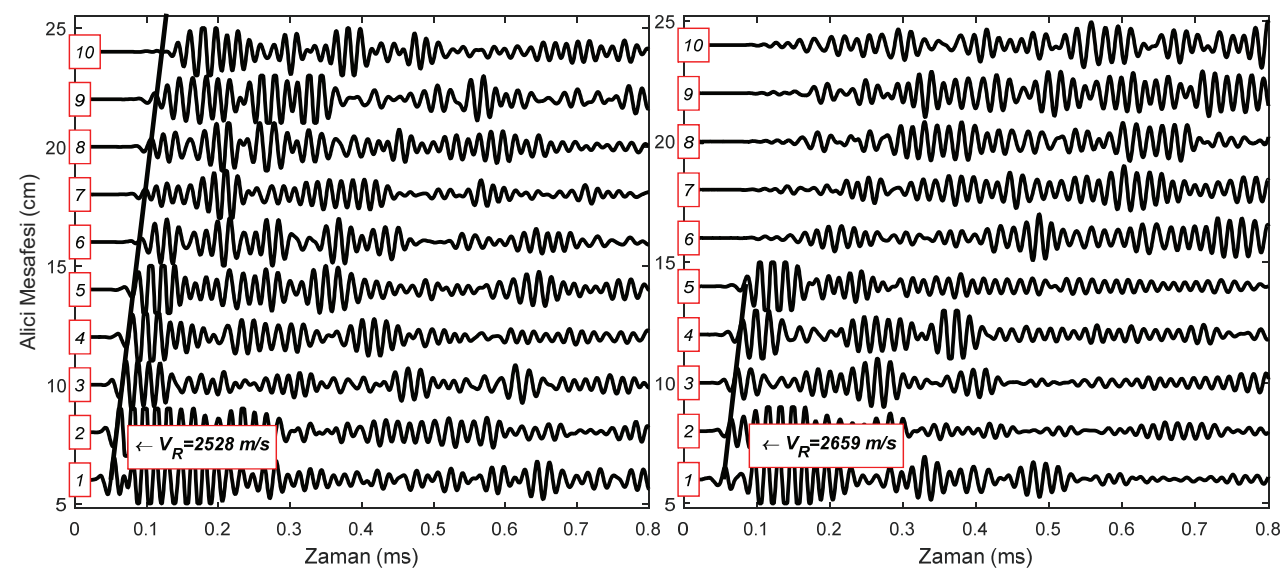

Şekil 4 - Ultrasonik dalga sinyalleri (sol) B1 ve (săg) B7

\section{DIYAGNOSTIK İNDEKSLER İÇİN VERİ ANALİZi}

\subsection{Malzeme Sönüm Katsayısı}

Kiriş numunelerindeki çatlakların dalga enerjisi üzerinde sönümleyici etkisi, Şekil 5 'te farklı çatlak derinliklerine sahip B1, B3 ve B7 kirişleri için verilmiş olan 'frekans vs. alıcı mesafesi' spektrumunda açıkça görünmektedir. Sağlam numune olan B1 için tüm frekanslar kiriş boyunca yayılımına devam etmekte iken, çatlak derinliği artıkça daha küçük frekanslar, başka bir deyişle sadece çatlaktan geçebilecek büyüklükteki dalga-boyları yayılımına devam edebilmektedir. Çatlak derinliği (94 mm) neredeyse kiriş en-kesitine (100 mm) denk olan B7 için ise hiçbir frekans çatlaktan geçememiştir. Çatlağın frekanslar üzerindeki bu sönümleyici etkisi Denklem 1'de verilen sönümleme katsayısı ile ölçülebilinir. Denklem 1, tüm spektral enerji yerine, sadece seçilmiş frekansların enerjisini dikkate alacak şekilde adapte edilirse, farklı frekansların sönümlenme seviyelerini inceleyerek çatlak derinliğini tayin etmek mümkün olacaktır. Bu sebeple burada, Denklem 1'deki $A_{i}$ parametresi için klasik Fourier dönüşümü yerine wavelet dönüşümü (WT) sonucunda elde edilen değerler tercih edilmiştir. Klasik Fourier dönüşüm zaman domaininden frekans domaine dönüşümü sağlarken, aşağıdaki denklemde gösterilmiş olan sürekli wavelet dönüşüm (CWT) zaman domainini kaybetmeden sinyallerin frekans bantlarına ayrılmasını sağlar [21]:

$W_{\psi}(a, t)=\frac{1}{\sqrt{a}} \int_{-\infty}^{\infty} p(t) \psi^{*}\left(\frac{t-t^{\prime}}{a}\right) d t$ 
Burada, $a$ dilatasyon (ölçek) parametresi; $t^{\prime}$ konum (zaman kayması) parametresi; $p(t)$ zaman sinyalidir. $\psi^{*}$ ise ana dalgacık fonksiyonunun karmaşı eşleniğini ifade eder. Wavelet dönüşümü, Denklem 6'da ifade edildiği üzere, ölçeklendirilebilen ve kaydırılabilen bir dalgacık fonksiyonu kullanılarak gerçekleştirildiğinden, belirli bir frekansın zaman domainde takibini sağlar. Bununla birlikte, daha geniş bir frekans aralığı hedeflenirse, o zaman, CWT yerine, ayrık wavelet dönüşümü (DWT) tercih edilmelidir. DWT kullanılarak, herhangi bir $p(t)$ sinyali, her biri belirli bir frekans bandı genişliği ile ilişkili olan altsinyallere ayrıştırılabilinir. Bunun için DWT’de aşağıda verilmiş olan ayrıklaştırılmış ana dalgacık fonksiyonu kullanılmalıdır [22]:

$\psi_{j, k}(t)=\frac{1}{\sqrt{a_{0}^{j}}} \psi\left(\frac{t-k \tau_{0} a_{0}^{j}}{a_{0}^{j}}\right)$

$j$ ve $k$ tamsayı olup, burada sabit dilatasyon adımı $a_{0}=2$ ve konum faktörü $\tau_{0}=1$ 'dir.

$\mathrm{Bu}$ çalışmadaki ultrasonik testlerde kaydedilen sinyaller DWT ile işlenerek dalga sönümü hesaplanmıştır. Ham sinyaller önce, Daubechies (dbn18) fonksiyonunun [23] ana dalgacık olarak kullanıldığı DWT ile alt-sinyallerine ayrıştırılmıştır. Bu alt-sinyallerin her biri belirli bir frekans bant genişliği ve bu nedenle belirli bir dalga boyu aralığı ile ilişkilidir. Örnek olarak, B1 üzerinde kaydedilmiş sinyallerin DWT ile ayrıklaştırılmış alt-sinyallerinden elde edilmiş spektral enerjilerdeki mesafe ile gözlemlenen sönüm eğrileri Şekil 6'da gösterilmiştir. Her sönüm eğrisi belli bir frekans bandını temsil etmekte olup yüksek frekans aralıklarında daha hızlı sönümlenirken, düşük frekanslarda bu sönümleme daha azdır. $\mathrm{Bu}$ çalışmada, DWT ile elde edilmiş alt-sinyaller arasında, verici transdüserin frekans aralığı ile örtüştüğü için, 31-62,5 kHz frekans bant aralığını içeren alt-sinyaller tercih edilmiştir. Bu frekans aralığının spektral enerjisi Fourier dönüşüm kullanılarak hesaplandıktan sonra sönüm katsayısı tayin edilmiştir.

Şekil 7(sol)'da gösterilen sönüm eğrileri, B1 ve B7 numuneleri için 31-62,5 kHz frekans bant aralığını içeren alt-sinyallerin spektral enerjisindeki düşüşü temsil eder. Numunelerden elde edilen sönüm eğrileri Denklem 1 ile uyumlu olarak $e^{\alpha\left(x_{1}-x_{i}\right)}$ fonksiyonuna regresyon yapılarak sönüm katsayısı $\alpha$ hesaplanmıştır. Her kiriş için hesaplanan $\alpha$ katsayısı, maksimum katsayı ile normalize edilerek, Şekil 7(sağ)'da verilmiştir. Kontrol kirişi (B1) ile en fazla hasar görmüş kiriş (B7) arasında $\alpha$ katsayısı neredeyse 18 katlık bir artış göstermiştir. Şekil 7(sağ) B2, B3 ve B5'teki çatlak derinliği ile B4, B6 ve B7'dekinin birbirine yakın olduğunu işaret etmektedir. Seçilen alt-sinyal 4 ile $8 \mathrm{~cm}$ arasındaki dalga boylarına tekabül ettiği için, B4, B6 ve B7'de çatlak derinliğinin en az $8 \mathrm{~cm}$ olduğu tahmin edilebilinir. Şekil 7(sağ)'da gözlenen $\alpha$ katsayısındaki değişim, B2, B3, B6 ve B7 için Tablo 1'de verilen yüzeysel çatlakların görsel muayene ile ölçülen derinliği ile uyum içerisindedir. B4 ve B5 ise üzerlerinde gözlenen yüzey çatlaklarının derinliği ile uyum göstermemektedir. Bu durumun yüzeyde ölçülmüş olan çatlak derinliğinin kiriş en-kesiti boyunca değişken olmasından kaynaklandığı düşünülmektedir. Son olarak Şekil 8'de normalize edilmiş sönüm katsayıları karşılık geldikleri görsel muayene ile ölçülmüş çatlak derinliği için grafik olarak sunulmuştur. $\mathrm{Bu}$ grafiğe göre sönüm katsayısı $\alpha$ genel olarak çatlak derinliği ile orantılı olarak artmakta olup, hasarsız numune B1'in dahil edilmediği lineer regresyon analizi sonucunda determinasyon katsayısı $\mathrm{R}^{2}=0.767$ olarak belirlenmiştir. 

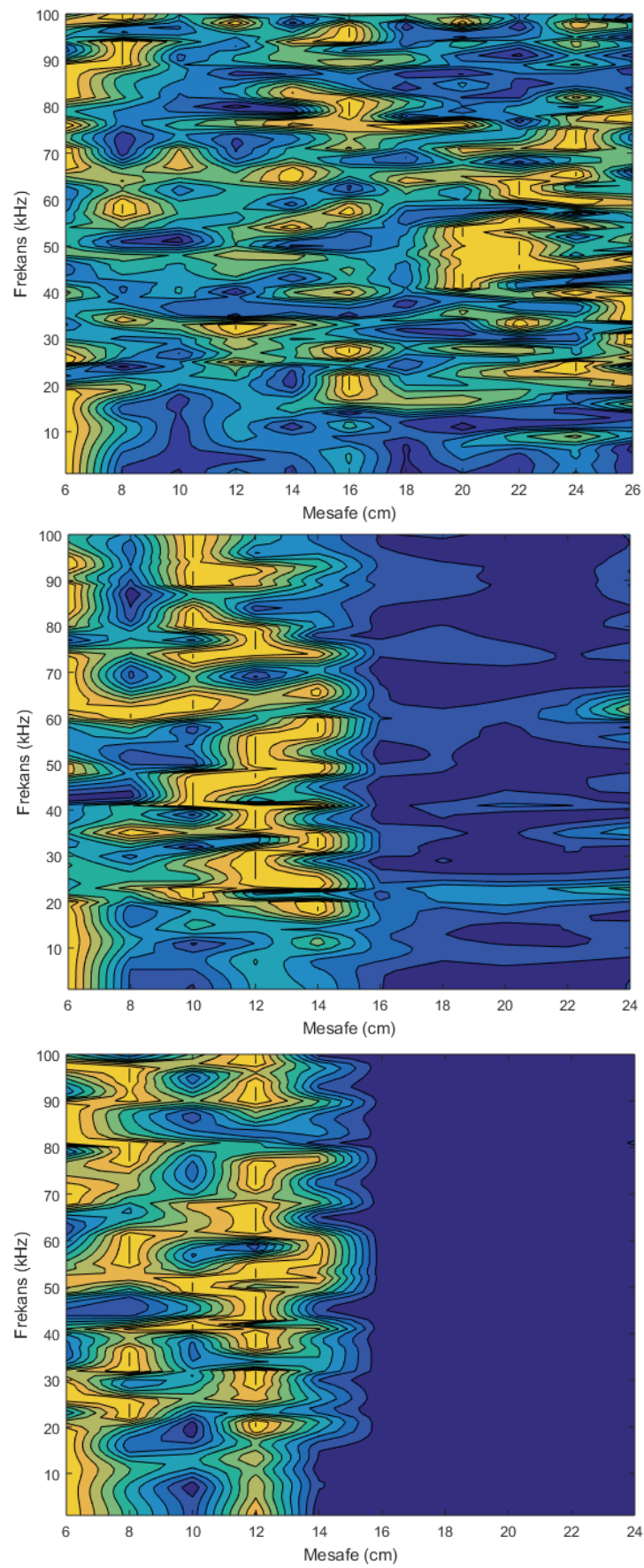

Şekil 5 - Spektrum vs. mesafe (üst) B1, (orta) B3 ve (alt) B7 


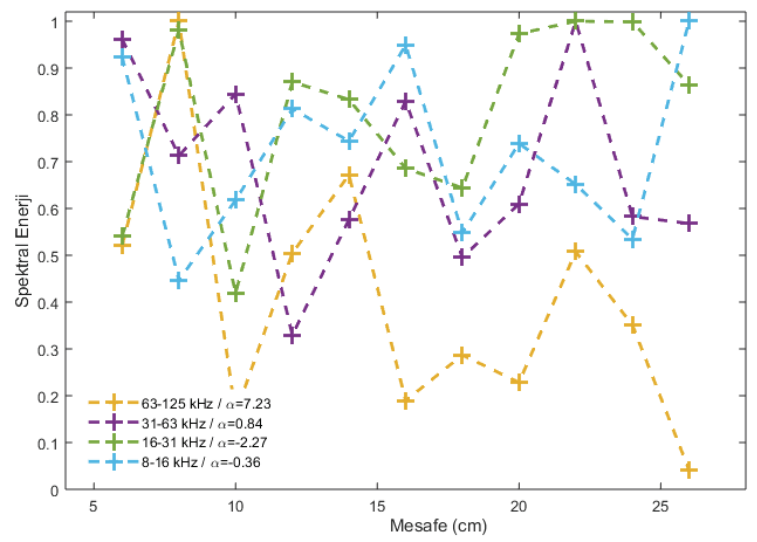

Şekil 6 - Kiriş B1 için alt-sinyallerin spektral enerjisi
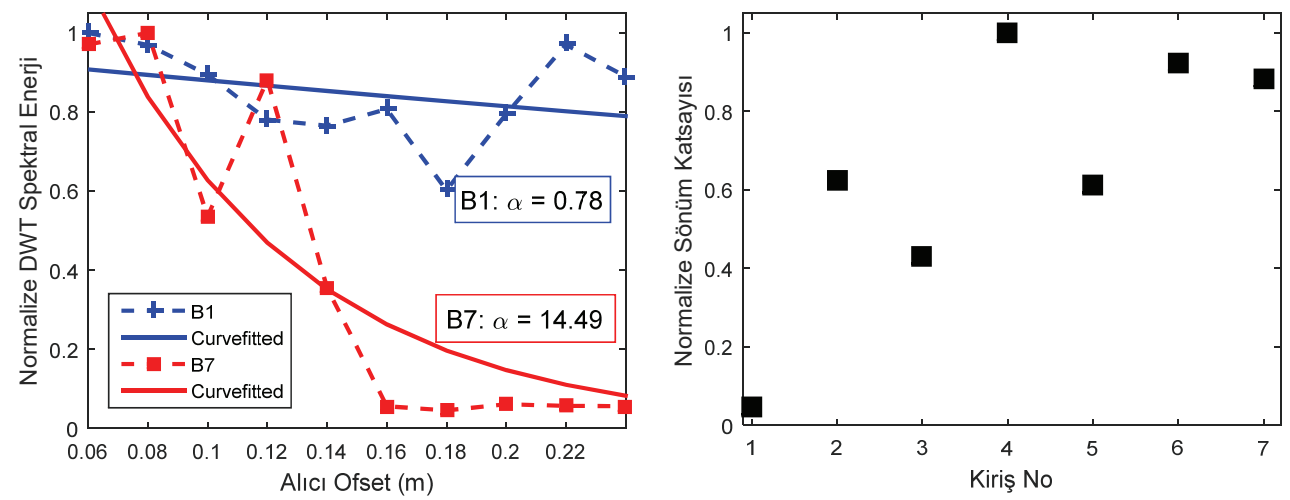

Şekil 7 - (sol) Sönüm ĕgrileri, (să̆) her bir kiriş için normalize edilmiş sönüm katsayısı

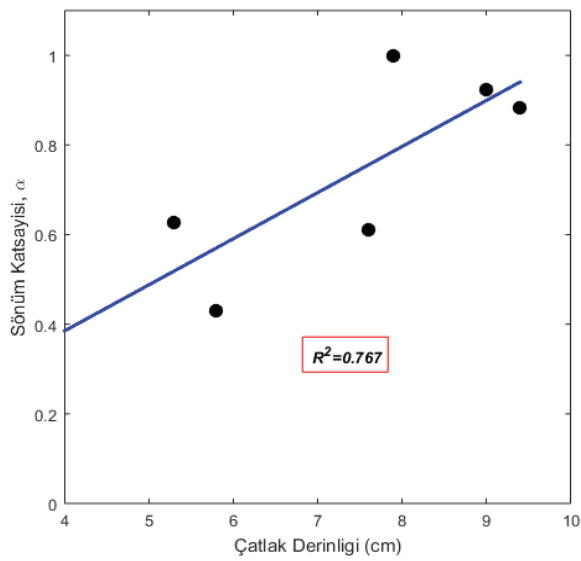

Şekil 8 - Normalize edilmiş sönüm katsayısı vs. çatlak derinliği 


\subsection{Faz Hızı Dağılımı (Dispersiyon)}

Bölüm 2.2'de açıklandığı gibi $f-k$ spektrumu üzerinde dalga yayılımındaki dağılım (dispersiyon) tespit edilebilinmektedir. Dağılımın tespitinin de ötesinde, bu dağılımın derecesinin belirlenmesi de mümkündür. Bunun için öncelikle $f-k$ spektrumundaki maksimum değerlere karşılık gelen dalganumarası $k$ tespit edilerek dispersiyon eğrisini oluşturan faz hızları $V_{p h}$ Denklem 4 ile hesaplanmalıdır. Homojen bir cisimde, dispersiyon eğrisi Rayleigh hızına $V_{R}$ eşit olup, düz bir çizgi olarak görünür. Bununla birlikte, herhangi bir çatlak veya kusur olması durumunda ise faz hızlarında $V_{p h}$ sabit Rayleigh hızına $V_{R}$ kıyasla sapma meydana gelecektir ki, bu değişim de çatlak derinliğini tahmin etmek için kullanılabilinir. Bu çalışmada, testlerden elde edilen dispersiyon eğrileri, faz hızlarındaki $V_{p h}$ toplam dispersiyonu dikkate alan çatlak seviyesi ile orantılı "dağılım endeksi $D I$ " adı verilen tanı indeksini hesaplamak için, kullanılmıştır [24]:

$D I^{\langle\text {Kiriş\# }\rangle}=\sum\left|V_{p h}^{\langle\text {Kiriş\# }\rangle}(f)-V_{p h}^{\langle\text {Referans }\rangle}(f)\right| / V_{p h}^{\langle\text {Referans }\rangle}(f)$

Dağılım indeksi DI herhangi bir kirişte çatlağın neden olduğu faz hızlarındaki kümülatif değişiminin referans bir dispersiyon eğrisine göre normalize edilmesiyle elde edilmektedir.
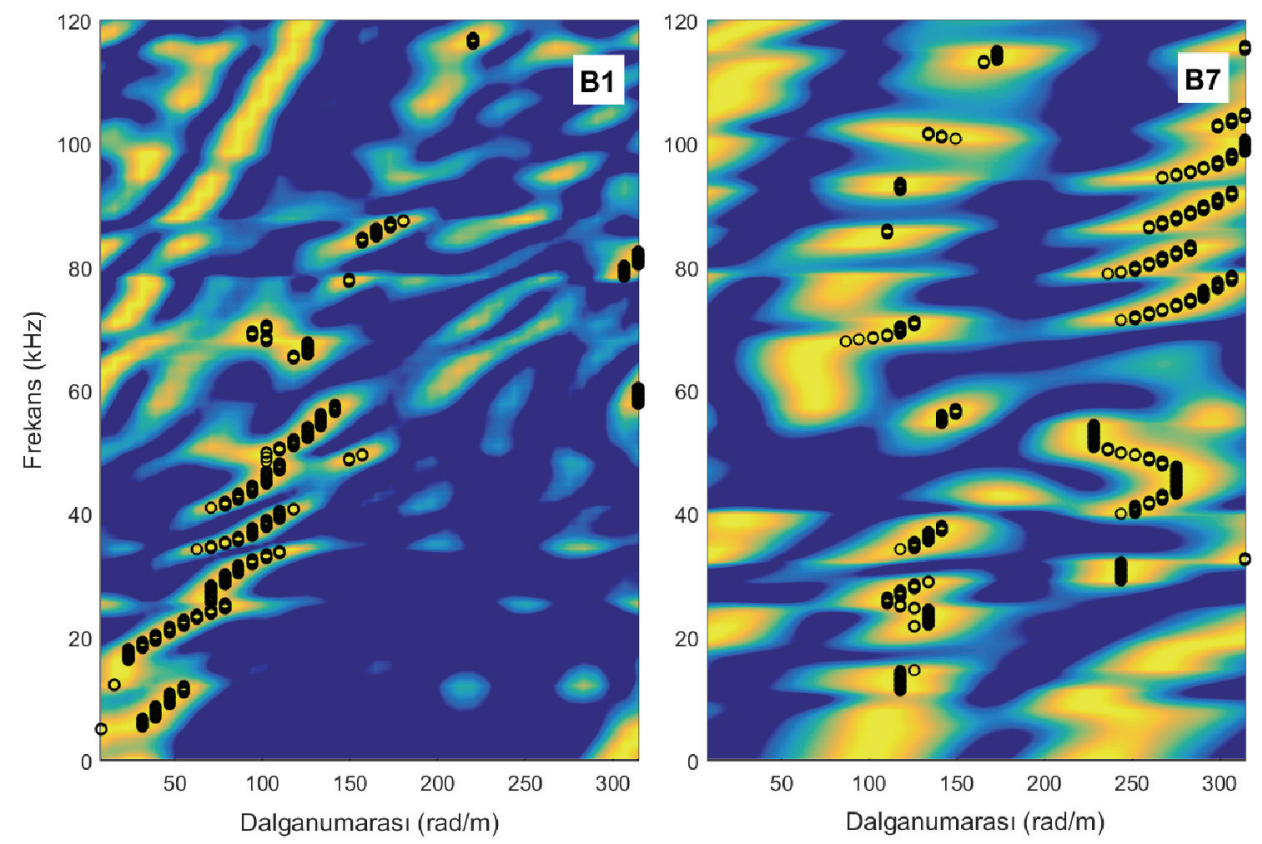

Şekil 9 - $f$ - k spektrumu (a) B1, (b) B7

Şekil 9'da örnek olarak B1 ve B7 kirişlerinde kaydedilen sinyal seti üzerinde gerçekleştirilen iki boyutlu Fourier dönüşümü sonucu elde edilen $f-k$ spektrumları verilmiştir. Şekil 9'da 
B7'daki çatlağın faz hızı üzerindeki dağılım etkisi, sağlam kiriş B1 ile kıyaslandığında, $f$ $k$ spektrumu üzerinde açıkça gözlenmektedir. Bu spektrumlarda işaretlenen maksimum değerlere karşılık gelen dalganumarası $k$ seçilerek Denklem 4'e yerleştirilmiş ve $V_{p h}$ hesaplanarak Şekil 10'daki dağılım eğrileri elde edilmiştir. Şekil 10'da testlerden elde edilen dağılım eğrilerine ek olarak teorik dispersiyon eğrileri de gösterilmiştir. İlk anti-simetrik (eğilme) modunu temsil eden dağılım eğrisini de içeren bu teorik faz hızı eğrileri aşağıda verilen "Rayleigh-Lamb frekans denklemi" [25] kullanılarak elde edilmiştir:

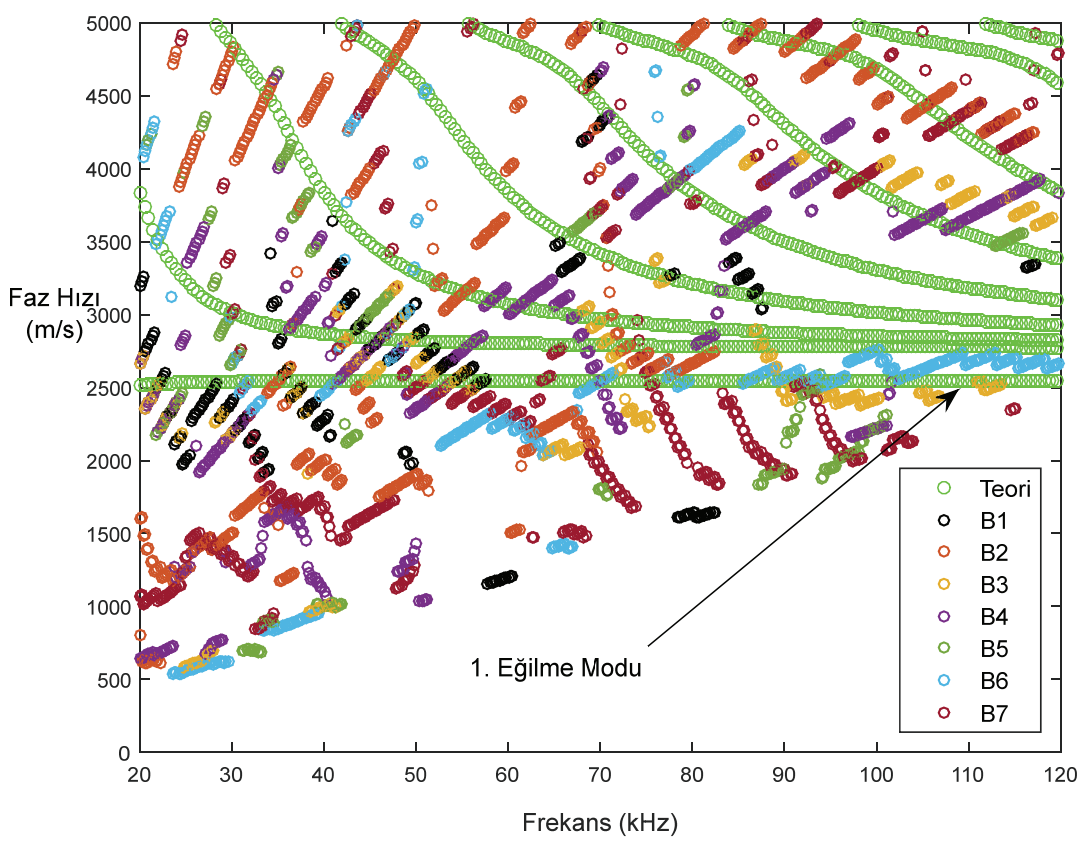

Şekil 10 - Dispersiyon ĕgrileri

$\frac{\tanh (\beta d)}{\tanh (\alpha d)}+\left[\frac{4 \alpha \beta k^{2}}{\left(k^{2}-\beta^{2}\right)^{2}}\right]^{ \pm 1}=0 \quad\left\{\begin{array}{c}+1=\text { symmetrical } \\ -1=\text { antisymmetrical }\end{array}\right.$

Burada $\alpha^{2}=k^{2}-\omega^{2} / V_{P}^{2}$ ve $\beta^{2}=k^{2}-\omega^{2} / V_{S}^{2} . V_{P}$ ve $V_{S}$ sirasiyla P-dalgası ve S-dalgas1 hızları; $k, \omega$ ve $d$ ise sırasıyla dalganumarası, açısal frekans ve cisim kalınlığıdır. Denklem 9 'da ihtiyaç duyulan S-dalga hızı $V_{S}$, Rayleigh dalga-hızı $V_{R}$ ve Poisson oranı $v$ kullanılarak aşağıdaki eşitliğin yardımıyla bulunur [25]:

$V_{S}=\frac{1+v}{0.87+1.12 v} V_{R}$

Burada teorik faz hızı eğrileri hesabı için P-dalga hızı $4513 \mathrm{~m} / \mathrm{s}$, Rayleigh-dalga hızı 2528 $\mathrm{m} / \mathrm{s}$ (B1 için ölçülen), cisim kalınlığ $10 \mathrm{~cm}$ ve Poisson oranına $v=0.2$ olarak kabul edilmiștir. Teorik faz hızı eğrileri hesabının akabinde, Şekil 10'da gösterilen testlerden elde edilmiş olan dağılım eğrilerindeki toplam varyasyon, Denklem 8'de tanımlanan dağılım indeksi $D I$ ile ölçülmüsstür. Denklem 8'de ihtiyaç duyulan referans dispersiyon eğrisi Şekil 
10'da gösterilmiş olan Rayleigh-Lamb frekans denkleminden (Denklem 9) elde edilmiş olan 1. eğilme modunu temsil eden eğri olarak seçilmiştir. Bu eğri çatlaksız kirişte sabit hızla ilerleyen yüzey dalgalarını temsil ettiği için tercih edilmiştir. Her bir kiriş için Denklem 13 ile elde edilmiş olan DI değerleri normalize edilerek Şekil 11'de gösterilmiştir. DI, B2 haricinde, genel olarak hasar seviyesi ile uyumlu olarak artmaktadır. Kontrol numunesi B1, hasar içermediği için, sadece kirişin geometrisinden kaynaklanan dalga dağılımı sebebiyle en küçük indeksin, $D I=0.165$, elde edildiği numunedir. B2'de ise beklenmeyen aykırı bir DI değeri elde edilmiştir. B2'deki anormal dalga dağılımın sebebi netleştirilememiş olmakla birlikte, muhtemel sebebinin test sırasında ekipman veya operatör kaynaklı bir kusur olduğu düşünülmektedir. Dağılım indeksinin çatlak derinliği ile olan ilişkisini daha iyi kavramak amacıyla, Şekil 12'de normalize edilmiş DI karşılık geldikleri görsel muayene ile ölçülmüş çatlak derinliği için grafik olarak sunulmuştur. Bu grafiğe göre, daha önce sönüm katsayısında da gözlemlendiği gibi, kirişlerdeki toplam dispersiyonun göstergesi olan $D I$ genel olarak çatlak derinliği ile orantılı olarak artmaktadır. Hasarsız numune B1 ve aykırı değere sahip B2'nin dahil edilmediği Şekil 12'de verilen beş numune için yapılan lineer regresyon analizi sonucunda determinasyon katsayısı $R^{2}=0.979$ olarak belirlenmiştir.

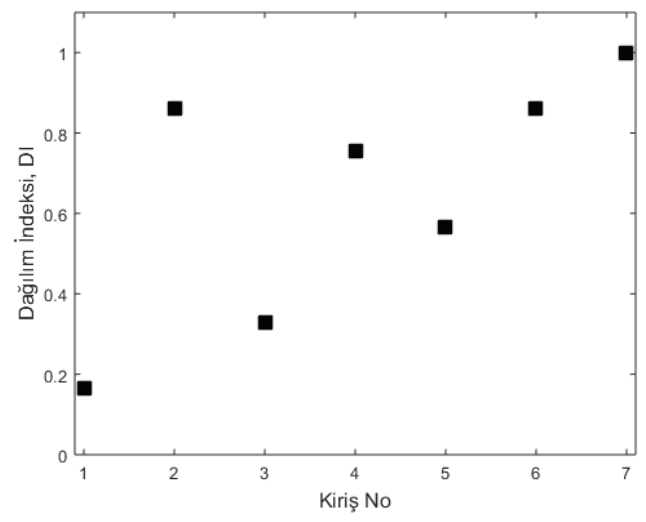

Şekil 11 - Her bir kiriş için DI

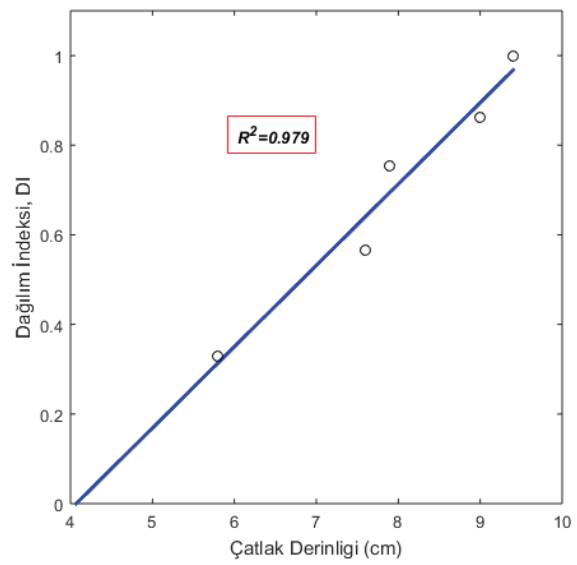

Şekil 12 - DI vs. çatlak derinliği 


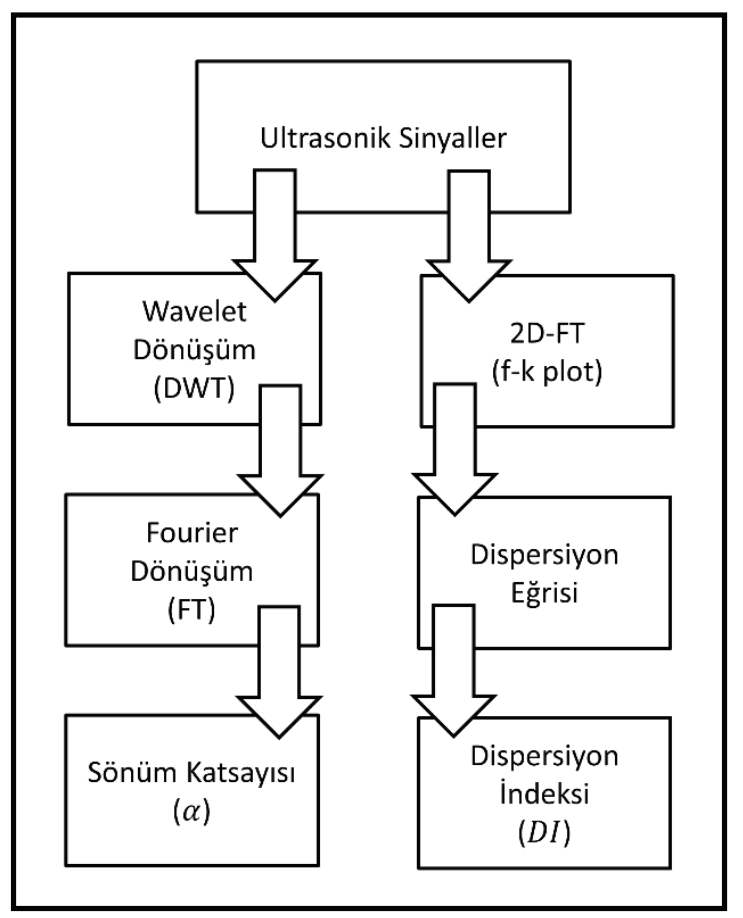

Şekil 13 - Algoritma akış diyagramı

\section{SONUÇ VE ÖNERILLER}

Burada sunulan araştırma kapsamında, çelik-lif takviyeli betonlarda eğilme çatlağı derinliği tayini için çok-kanallı ultrasonik test konfigürasyonu kullanılarak, yüzey dalgalarının genel dağılım davranışını temsil eden dağılım indeksi DI ilk kez elde edilmiştir. Eğilme çatlaklarının derinliklerinin tayini için geliştirilen diyagnostik algoritmaların akış şeması Şekil 13'te tasvir edilmiş olup, Tablo 2'de ise yukarıda elde edilmiş sonuçlar özet olarak sunulmuştur. Sonuç olarak elde edilen bulgular ve öneriler aşağıdaki gibi özetlenebilinir:

- Ultrasonik testlerden elde edilen tanı indeksleri, malzeme sönüm katsayısı $\alpha$ ve dağı̆lım indeksi $D I$, genel olarak çatlak derinliği ile doğru orantılı olarak artış göstermektedir.

- $\mathrm{Bu}$ iki indeks arasında, regresyon analizi sonucunda elde edilen $\mathrm{R}^{2}$ değerleri dikkate alındığında, $D I$ indeksinin $\mathrm{R}^{2}=0.979$ ile $\alpha$ katsayısına $\left(\mathrm{R}^{2}=0.767\right)$ göre daha güvenilir bir tanı indeksi olduğu ifade edilebilinir.

- $\quad D I$, çatlağın dispersiyon eğrisinde neden olduğu varyasyonu tek bir tanı parametresini indirgeyerek, ultrasonik test verilerinin yorumlanmasında kolaylık sağlamaktadır.

- $\quad D I$, incelenen yedi numunenin altısında (\%86), görsel inceleme ile ölçülen çatlak derinlikleri ile uyumluluk göstermiştir. 
- Her bir indeksin gerek test düzeneği gerekse veri işleme tekniklerinin kendine özgü olarak hata ihtiva edebileceği düşünüldüğünde, gerçekçi bir tespit yapmak için tek bir tanı yerine birden fazla indeksin dikkate alınmasının daha doğru sonuçlar vereceği aşikardır. Bu sebeple, ileride farklı yöntemler ile elde edilmiş, burada bahsi gecen tanı indekslerinin, son zamanlarda yaygınlaşmış olan veri-kaynaştırma [26] metotları ile kaynaştırılarak tek ama güvenirliliği arttırılmış tanı indeksi elde etmeye dönük çalışmalar yapılması uygun olacaktır.

\section{Tablo 2 - Özet Sonuçlar}

\begin{tabular}{|c|c|c|c|c|}
\hline Kiriş & $\begin{array}{c}\text { CMOD } \\
(\mathbf{m m})\end{array}$ & $\begin{array}{c}\text { Çatlak } \\
\text { Derinliği } \\
(\mathbf{c m})\end{array}$ & $\boldsymbol{\alpha}^{[\mathbf{2}]}$ & $\boldsymbol{D I}^{[\mathbf{3}]}$ \\
\hline B1 & N/A & N/A & 0.047 & 0.165 \\
\hline B2 & 1.00 & 5,3 & 0.626 & 0.860 \\
\hline B3 & 1.25 & 5,8 & 0.429 & 0.330 \\
\hline B4 & 1.50 & 7,9 & 1 & 0.755 \\
\hline B5 & 1.75 & 7,6 & 0.610 & 0.566 \\
\hline B6 & 2.00 & 9,0 & 0.923 & 0.861 \\
\hline B7 & 2.25 & 9,4 & 0.882 & 1 \\
\hline
\end{tabular}

[1] Görsel muayeneye dayalı ölçüm, [2] Normalize edilmiş malzeme sönüm katsayıs1, [3] Dă̆glım indeksi

\section{Teşekkür}

Bu proje Türkiye Bilimsel ve Teknolojik Araştırma Kurumu'nun (TÜBİTAK) desteği ile gerçekleştirilmiştir. [BİDEB 2232 Yurda Dönüş Bursu, Proje No: 118C022].

\section{Kaynaklar}

[1] ASTM C597-16. (2016) Standard Test Method for Pulse Velocity Through Concrete. ASTM International, West Conshohocken, PA.

[2] ACI 228.2R-13. (2013) Report on Nondestructive Test Methods for Evaluation of Concrete in Structures. ACI Committee 228

[3] Daniels, D. J. (2004). Ground Penetrating Radar. Institution of Engineering and Technology.

[4] ACI Committee 222R-01. (2010). Protection of metals in concrete against corrosion, American Concrete Institute, Farmington Hills, MI. 
[5] Song, W., Popovics, J. S., Aldrin, J. C., and Shah, S. P. (2003). Measurement of surface wave transmission coefficient across surface-breaking cracks and notches in concrete. Journal of the Acoustical Society of America, 113(2), 717-725. doi:10.1121/1.1537709

[6] Tallavo, F., Cascante, G., and Mahesh, P. (2009). Experimental and Numerical Analysis of MASW Tests for Detection of Buried Timber Trestles: Soil Dynamics and Earthquake Engineering, 29(1), 91-102.

[7] Nasseri-Moghaddam A., Phillips C., Cascante G., and Hutchinson J. (2007). Effects of underground cavities on Rayleigh waves-numerical and experimental study. Soil Dyn Earthquake Eng, 27(4), 3000-13.

[8] Hassan, A., Nasseri-Moghaddam, A., and Cascante, G. (2011). Use of numerical simulation for the identification of underground voids using the MASW test: in Proceedings: 14th PanAm CGS Geotechnical Conference.

[9] Kirlangic, A. S., Cascante, C., and Polak, M. (2016). Assessment of concrete beams with irregular defects using surface waves. ACI Materials, 113(1), 73-81.

[10] Rodríguez-Roblero, M. J., Ayon, J. J., Cascante, G., Pandey, M. D., Alyousef, R., and Topper, T. (2019). Application of correlation analysis techniques to surface wave testing for the evaluation of reinforced concrete structural elements: NDT and E International, 102, 68-76. doi:10.1016/j.ndteint.2018.11.003.

[11] Aggelis, D. G., Shiotani, T., and Polyzos, D. (2009). Characterization of surface crack depth and repair evaluation using Rayleigh waves. Cement \& Concrete Composites, 31 (1), 77-83.

[12] Zerwer, A., Polak, M., and Santamarina, J. C. (2003). Rayleigh Wave Propagation for the Detection of Near Surface Discontinuities: Finite Element Study. Journal of Nondestructive Evaluation, (22)2, 39-52.

[13] Zerwer, A., Polak, M., and Santamarina, J. C. (2005) Detection of Surface Breaking Cracks in Concrete Members Using Rayleigh Waves. Journal of Environmental \& Engineering Geophysics, 10(3), 295-306.

[14] Yang, Y., Cascante, G., and Polak, M. (2009). Depth detection of surface-breaking cracks in concrete plates using fundamental Lamb modes. NDT \& E International, 42(6), 501-512.

[15] Kirlangic, A. S., Cascante, C., and Polak, M. (2015). Condition Assessment of Cementitious Materials Using Surface Waves in Ultrasonic Frequency Range. ASTM International Geotechnical Testing Journal, 38(2), 1-11.

[16] Aggelis, D. G., Leonidou, E., and Matikas, T. E. (2012). Subsurface crack determination by one-sided ultrasonic measurements. Cement and Concrete Composites, 34(2), 140-146. doi:10.1016/j.cemconcomp.2011.09.017

[17] Richart, F. E. Jr., Hall, J. R. and Woods, R. D. (1970). Vibrations of Soil and foundations. Prentice-Hall, Englewood Cliffs, New Jersey.

[18] Park, C. B., Miller, R. D., and Xia, J. (1997). Multichannel Analysis of Surface Waves, Kansas Geological Survey, Lawrence, KS. 
[19] EN 14651. (2005). Test method for metallic fibre concrete - Measuring the flexural tensile strength.

[20] EN 12390-3. (2019). Testing hardened concrete - Part 3: Compressive strength of test specimens.

[21] Addison, P. (2002). The Illustrated Wavelet Transform Handbook: Introductory Theory and Applications in Science, Institute of Physics Publishing, Bristol and Philadelphia.

[22] Mallat, S. G. (1989). A theory for multiresolution signal decomposition: The wavelet representation. IEEE Transactions on Pattern Analysis and Machine Intelligence, 11(7), 674-693.

[23] MATLAB. (2010). version 7.10.0 (R2010a). Natick, Massachusetts: The MathWorks Inc.

[24] Kirlangic, A. S., Cascante, G., and Salsali, H. (2020). New Diagnostic Index Based on Surface Waves: Feasibility Study on Concrete Digester Tank. Journal of Performance of Constructed Facilities, 34(6). doi:10.1061/(ASCE)CF.1943-5509.0001522.

[25] Graff, K. F. (1975). Wave Motion in Elastic Solids, Ohio State University Press, Belfast.

[26] Ploix M-A., Garnier, V., Breysse, D., and Moysan, J. (2011). NDE data fusion to improve the evaluation of concrete structures. NDT E Int, 44(5), 442-448. doi:10.1016/j.ndteint.2011.04.006. 